URL de la revista: https://revistas.uca.es/index.php/cifa

\title{
Cuando la Casa de la Camorra se convirtió en Escuela de Comercio de Cádiz
}

\author{
Juan Antonio Vila Martínez \\ Profesor del Instituto de Enseñanza Secundaria “Jorge Juan” de San Fernando \\ (Cádiz) \\ casadelacamorra@gmail.com
}

\begin{abstract}
RESUMEN: Entre los usos del edificio conocido como la Casa de la Camorra, que se construyó a finales del siglo XVIII en la entonces calle Empedrador (actualmente Arbolí) de Cádiz, conocimos su ocupación como Escuela de Comercio entre los años 1906 y 1918. Los documentos generados por dicha Escuela actualmente se conservan en el Archivo de la Universidad de Cádiz que nos han aportado unas interesantes informaciones. Utilizamos para la investigación de manera preferente el contrato de arrendamiento del edificio y las actas del Claustro de Profesores de la Escuela.
\end{abstract}

Palabras clave: Casa de la Camorra, Escuela de Comercio de Cádiz, Colegio de Farmacéuticos de Cádiz.

\section{How Casa de la Camorra turned into the Cadiz Business School}

ABSTRACT: Among the uses of the building known as 'Casa de la Camorra', which was built during the late eighteen century in Emperador's Street (currently named 'Arbolí') of Cádiz, we know its use as Business School between 1906 and 1918. The documents generated by this School are currently kept in the archive of the University of Cádiz, which have given us some interesting information. Preferably, we use for the research the leasing contract of the building and the proceedings of the Faculty.

Keywords: Casa Camorra, Cádiz Business School, Cádiz Pharmacist College.

Como si se tratase de un guiño a la Historia el edificio que veintisiete grandes comerciantes de 14 nacionalidades europeas labraron hacía 1783 para albergar una Tertulia Internacional en la gaditana calle Empedrador (actualmente conocida como DOI del artículo: http://dx.doi.org/10.25267/Cuad investig fondos arch UCA.2019.i1 Editorial ad UCA .08 
Arbolí) se convirtió en 1906 en la Escuela de Comercio de Cádiz. En el mismo lugar, veinte años antes, el propietario del adjunto Coliseo Italiano de la Ópera había habilitado una casa para que los integrantes de la Orquesta de la Compañía viviesen en "armonía". La amplia gama de sonidos musicales y verbales que la veintena de sus habitantes ofrecían provocó la denominación del lugar como "Casa de la Camorra”. El origen de dicha palabra se situaba en el Reino de Aragón en la Edad Media para denominar a los bandoleros de la zona y a su estrategia. El griterío de los asaltantes provocaba la huida de los mercaderes que abandonaban sus pertenencias en manos de los temidos bandoleros o "gamurri".

Una vez que en 1778, por diversos motivos, el Teatro de madera especializado en Ópera deja de tener uso, la casa de los músicos queda abandonada y es adquirida a "censo reservativo" (especie de acciones) por un amplio número de comerciantes que derriban la vivienda para sobre su pavimento construir un gran edificio de tres plantas. En la zona baja ubican un amplio Salón Bajo de 28 metros de profundidad con una hermosa fachada neoclásica labrada en piedra sedimentaria que servirá para realizar espectáculos teatrales y musicales que recordarían a los desaparecidos Teatros de Tragedia Francesa, que se ubicó en el Mentidero, y al mencionado cercano Coliseo de Ópera que también fue derribado. Sobre el nuevo Teatro se construyeron cinco grandes salas en dos alturas que tuvieron funciones diversas como Biblioteca, espacios de juegos y salas de reuniones donde seguramente se realizaban las transacciones económicas en el amplio trasiego comercial que desarrolló el puerto gaditano a finales del siglo XVIII y principios del XIX.

El edificio fue confiscado en 1808 al comenzar la Guerra de Independencia y durante los años siguientes sirvió como Depósito de Vestuario de las tropas, Depósito Hidrográfico y sede del Tribunal que juzgó al ex regente Lardizabal. Los antiguos propietarios no volvieron a reclamar su devolución sirviendo durante el siglo XIX como sede de numerosas instituciones culturales y recreativas. Entre 1826 y 1840 albergó a las escuelas lancasterianas de la Sociedad Económica Gaditana de Amigos del País y también al resto de secciones y la secretaría de la asociación. En 1841 sirvió de lugar de reunión de un grupo republicano que logró representación municipal.

En las décadas posteriores se convirtió en sede del Liceo Artístico y Literario (1844-1845), Sociedad o Círculo Filarmónico (1849-1854), Liceo Gaditano (18551858), Ateneo de Cádiz (1858-1862), y Círculo Artístico Recreativo (1862-1873) convirtiéndose su Teatro en el referente de los Bailes de Carnaval de los años centrales de la centuria.

Entre 1873 y 1877 sus salas se convirtieron nuevamente en escuelas de los Coros de la Inmaculada Concepción, quedando en los años siguientes en un estado de abandono probablemente por el amplio coste de su mantenimiento. Algunas referencias periodísticas nos hablan de bailes de Carnaval a principios de la década de los ochenta y 
la efímera existencia de un café cantante en 1884. A partir de 1885 y hasta finales del siglo el esplendor del edificio fue recuperado por la Academia Filarmónica Santa Cecilia que ubicó en sus salas el Conservatorio de Música y Declamación recuperando el Teatro para audiciones musicales y multitud de reuniones de diversa índole.

Conocíamos que el edificio había sido la sede de la Escuela Superior de Comercio entre los años 1906 y 1918 ${ }^{1}$. Esta Escuela estuvo ubicada desde su fundación en el Instituto de Enseñanzas Medias de la Plaza de San Agustín hasta el año 1897 que se trasladó a otro edificio alquilado de la calle Santo Cristo número 14, para posteriormente mudarse a la calle Ahumada número 15 de donde pasó a Arbolí número 5. Desde 1918 se ubicó en la calle Rafael de la Viesca hasta 1958 que pasó al edificio de la Glorieta de Simón Bolívar, construido expresamente para albergar la Escuela, ya con categoría de Escuela Profesional de Comercio, por el arquitecto racionalista Antonio Sánchez Esteve.

Entre los documentos que hemos encontrado en el Archivo de la UCA destacamos el contrato de alquiler entre la Escuela y el propietario Don Fausto Rupérez Herrera confirmando la propiedad, que ya conocíamos, al menos desde 1903 cuando se estableció en ese mismo lugar el Círculo Modernista presidido por Antonio Rodríguez más conocido por "El Tío de la Tiza". También consultamos las actas de las reuniones del Claustro de profesores que nos permitió conocer las cantidades que el arriendo comportaba y las ayudas que desde diversos organismos como Ayuntamiento y Diputación se lograban para acometer los gastos. Lucio Bascuñana García como Director de la Escuela a finales de 1906 firmó el contrato de arrendamiento antes mencionado. La Guía de Cádiz del año 1916 señalaba en la calle Arbolí número 5, es decir en la misma dirección de la Escuela, la sede del Colegio de Farmacéuticos de Cádiz que curiosamente entonces era presidido por el mismo Lucio Bascuñana ${ }^{2}$.

Tras ser Escuela de Comercio el edificio fue cabaret con el nombre de Kursaal Gaditano (1918-1930) compartiendo sede con la Sociedad Artística Gaditana (19241927), siendo también Casa del Pueblo (1931-1936). Desde una fecha en torno al comienzo de los años cuarenta se convirtió en Teatro Jaime Balmes sirviendo de sede estable a la Compañía de Títeres de La Tía Norica de Cádiz (1952-1961) antes de que edificio se convirtiese en el Colegio Público Jaime Balmes, más conocido como Arbolí, desde mediados de los sesenta hasta el año $2003^{3}$.

\footnotetext{
${ }^{1}$ Guilloto (1994). La carrera de Comercio en Cádiz, Cádiz, Servicio de Publicaciones UCA.

${ }^{2}$ Guía para el viajero en Cádiz (1915), Cádiz, Sociedad de Fomento del Turismo.

3 Romero (2018). "Una ciudad, una casa, una huella" en Vila Martínez, J.A. (editor), La Casa de la Camorra de Cádiz, pp.21-38.

DOI del artículo:

http://dx.doi.org/10.25267/Cuad investig fondos arch UCA.2019.i1 .08 
Imagen 1 y 2. Contrato de inquilinato de la casa de la calle Arbolí, $n^{\circ} 5$
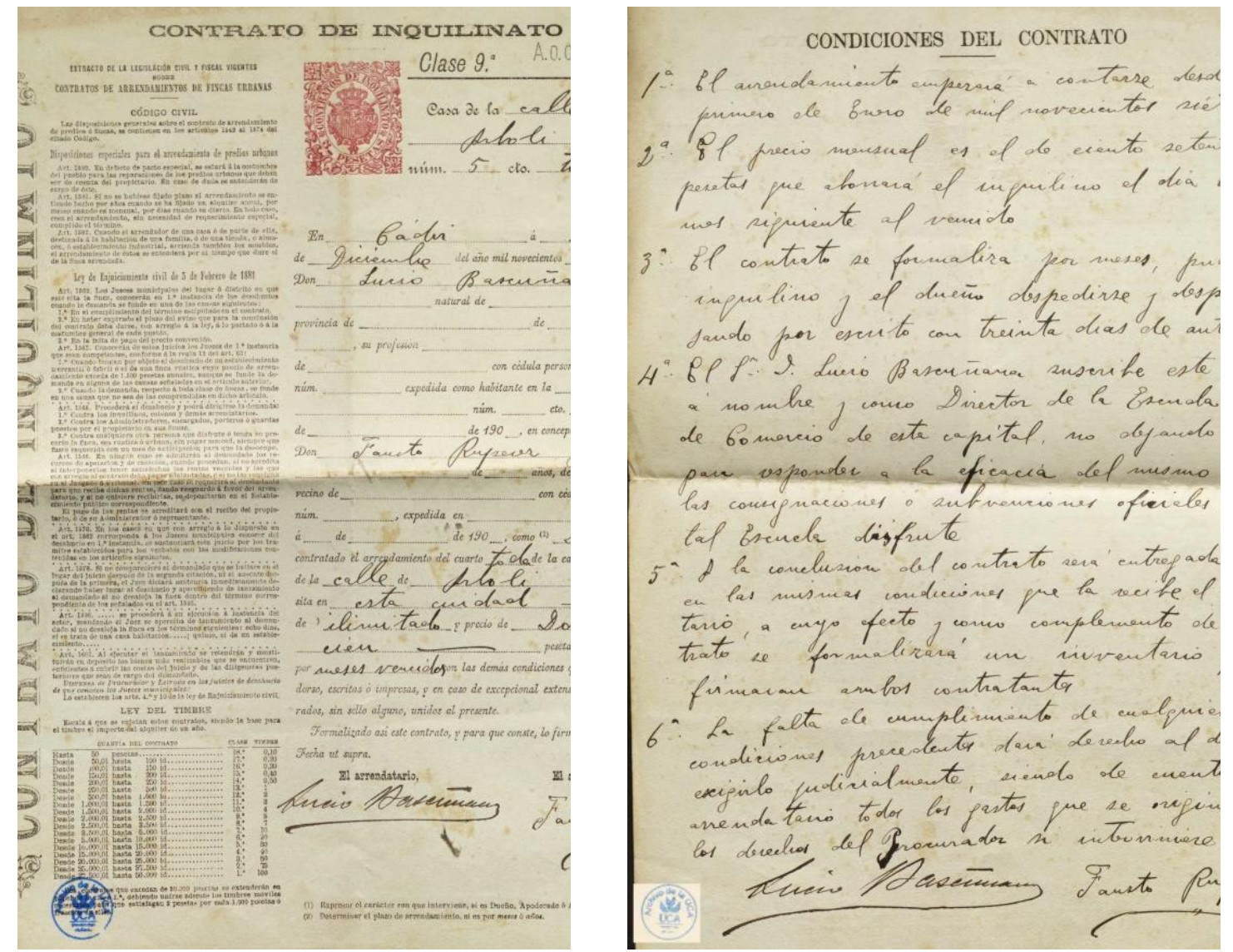

Fuente: Archivo de la Universidad de Cádiz, Fondo Escuela de Comercio, C-261-4 EC

\section{REFERENCIAS BIBLIOGRÁFICAS}

- Guilloto GonzÁlez, Fernando. La carrera de Comercio en Cádiz. Del arte de la contabilidad a las ciencias empresariales. Cádiz: Servicio de Publicaciones de la Universidad de Cádiz, 1994. ISBN: 84-7786-177-3.

- Vila Martínez, Juan Antonio (editor). La Casa de la Camorra de Cádiz. Sevilla, Ediciones Ende, 2018. ISBN: 978-84-17498-12-2. 